\title{
HLA-DPB1 and Epstein-Barr virus gp42 protein jointly contribute to the development of Hodgkin lymphoma
}

\author{
Hongyu Li^, Dan Liu, Xun Li \\ Breast Internal Medicine Department, The Third Affiliated Teaching Hospital of Xinjiang Medical University (Affiliated Cancer Hospital), Urumqi, \\ China \\ Contributions: (I) Conception and design: X Li; (II) Administrative support: X Li; (III) Provision of study materials or patients: H Li; (IV) Collection \\ and assembly of data: H Li, D Liu; (V) Data analysis and interpretation: H Li, D Liu; (VI) Manuscript writing: All authors; (VII) Final approval of \\ manuscript: All authors. \\ Correspondence to: Xun Li. Breast Internal Medicine Department, The Third Affiliated Teaching Hospital of Xinjiang Medical University (Affiliated \\ Cancer Hospital), Urumqi, China. Email: smxlixun@sina.com.
}

\begin{abstract}
Background: Epstein-Barr virus (EBV) glycoprotein 42 (gp42) enters B lymphocytes by binding to the human leukocyte antigen II (HLA-II) on their surface, in a process involving other EBV proteins (e.g., gH/gL and gp350). From a latent state of infection, the virus may reactivate and enter into a rapid proliferation phase, which enables the further entry of EBV into B lymphocytes and epithelial cells, leading to tumor development. EBV is an oncogenic virus associated with Hodgkin lymphoma (HL), and gp42 is a key protein in EBV infection of B lymphocytes. However, the exact binding pattern and capacity of gp42 are unclear.

Methods: The patterns and morphologies of gp42 binding to HLA-DPB1 were obtained through molecular dynamics simulation. The binding efficiency of gp42 and HLA-DPB1 was verified by plasmid construction and flow cytometry.

Results: The $\beta$-chain of HLA-DPB1 and the $\alpha$-chain of gp42 formed a hydrogen-bonded complex, which was a hydrophilic protein with a resolution of 3.25. The binding efficiency between HLA-DPB1 and gp42 reached its peak (range, 26-31.3\%) at a gp42 protein concentration of $80 \mu \mathrm{g}$.

Conclusions: We can inhibit the binding of gp42 to HLA-DPB1 by reducing the concentration of gp42. In the subsequent experiments, we will verify whether the binding of gp42 to HLA-DPB1 can be prevented by breaking hydrogen bonds and destroying hydrophilicity. These data may provide certain reference value for the development and treatment of Hodgkin's lymphoma.
\end{abstract}

Keywords: Hodgkin lymphoma (HL); HLA-DPB1; gp42

Submitted Mar 23, 2020. Accepted for publication Jul 08, 2020.

doi: $10.21037 /$ tcr-20-2070

View this article at: http://dx.doi.org/10.21037/tcr-20-2070

\section{Introduction}

Despite having a high survival rate $(1,2)$, at least $80 \%$ of patients can be cured with current chemoradiotherapy, as many as $15-20 \%$ of patients with Hodgkin lymphoma (HL) experience relapse or develop a second tumor, and in advanced patients, less than 5 percent survive without treatment. HL is most common in children and adolescents (3), and boys are 2-3 times more likely to develop this malignancy (4). However, the etiologic and pathogenic mechanisms of HL have not yet been illuminated.

Epstein-Barr virus (EBV), a spherical, 180-200 nm DNA virus, is part of the gamma-herpesviruses subfamily. Structurally, EBV comprises a genome, capsid, and envelope. As a common human virus, a significant proportion of people

\footnotetext{
^ ORCID: 0000-0003-1587-4192.
} 


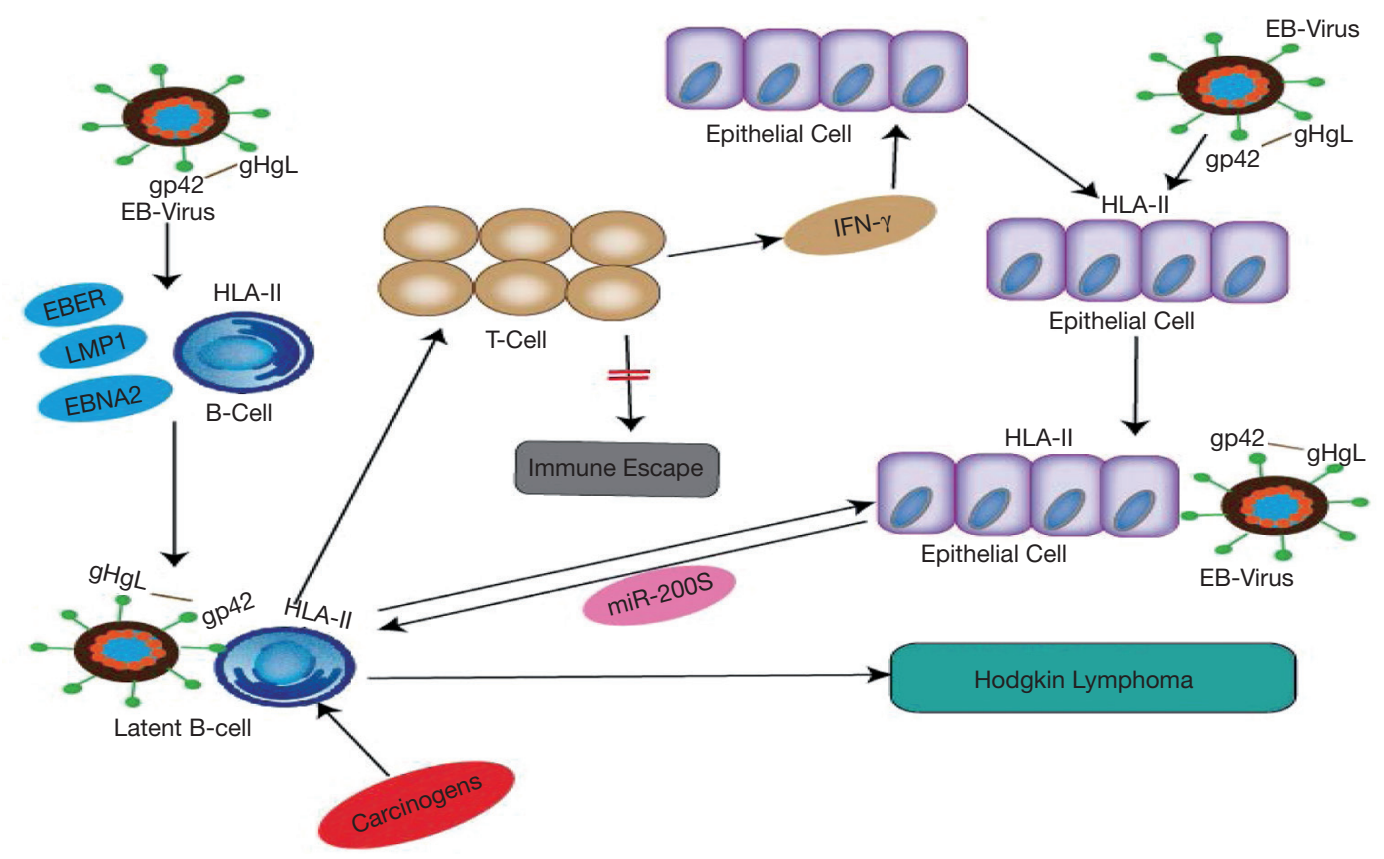

Figure 1 The development of Hodgkin lymphoma after EBV enters into epithelial cells and B lymphocytes.

acquire EBV at some point in their life. With tumorigenic potential (5), EBV is associated with the pathogenesis of nasopharyngeal carcinoma, gastric cancer, Burkitt lymphoma, and HL. Although HL typically originates in B-cells, epithelial cells also play a crucial role in its pathogenesis. After B lymphocytes are infected by EBV, the host does not experience any signs or symptoms directly; rather, the virus enters a stage of latent infection, during which the $\mathrm{B}$ cells secrete latency markers including EBV-encoded small RNAs (EBER), latent membrane protein 1 (LMP1), and EB nuclear antigen 2 (EBNA2) (5-7). These markers stimulate an immune response from $T$ cells, but the response is too weak to eliminate the persistent infection of EBV. Epithelial cells are jointly stimulated by interferon gamma (IFN- $\gamma$ ) released by T cells and the external EBV to produce HLA-II receptors and microRNA 200s protein (miR200s). miR200s can trigger B lymphocytes to transform from a state of latent infection to a state of malignant proliferation, resulting in the development of HL (Figure 1) (8).

What is novel in our paper is to explore the binding mechanism between HLA-DPB1 and gp42 protein on the surface of EBV. The gp42 protein on the surface of EBV determines membrane fusion and virus entry $(9,10)$. Gp42 and HLA-II molecules form a complex at a ratio of 1:1 (11). Gp42 also forms a high-affinity complex with $\mathrm{gH}$ and $\mathrm{gL}$ via the $\mathrm{N}$-terminus (12). The binding of the $\mathrm{C}$-terminus of gp42 to the $\beta$-chain of the HLA-II receptor (13) activates EBV infection of $\mathrm{B}$ cells and epithelial cells, leading to disease onset. HLA-DPB1 is a functional gene located on the $\beta$-chain of HLA-DP (14). In our previous study, sequence-based typing (SBT) was used to detect HLADPB1 genotypes in $100 \mathrm{HL}$ patients and 100 healthy adults. Four HL-related genotypes were identified: HLADPB1*04:01:01, 04:02:01, 09:01:01, and 14:01:01. Among them, HLA-DPB $1{ }^{*} 04: 01: 01$ had the highest expression level. In our current study, we further explored the pathogenic mechanisms of HL by studying the binding pattern between HLA-DPB1 and gp42.

\section{Methods}

\section{Molecular dynamics simulation}

The HLA-DPB1*04:01:01 genotype obtained by sequencing was further identified using BLAST in the UniProt (https://www.uniprot.org), which yielded that it was $98.4 \%$ P04440. The crystal structures of two proteins, P04440 (PDB:3LQZ) and gp42 (PDB:3FD4), were downloaded from the Protein Data Bank (PDB, http:// www.rcsb.org). Molecular dynamics simulations of these two proteins (3LQZ and 3FD4) were performed using the Discovery Studio 16.1 software as follows: (I) docking 
simulations of these two molecules were performed using Z-DOCK (Dock Proteins); (II) the optimal docking model was screened out using R-DOCK (Refine Docked Proteins); and (III) analysis of protein interface was performed for the optimal docking molecular model.

\section{Laboratory methods}

\section{Cell culture}

First, $10 \mathrm{~mL}$ of fetal bovine serum (FBS) (Excell Bio, China) was added into $90 \mathrm{~mL}$ of IMDM medium (GIBCO, USA). Then, $1 \mathrm{~mL}$ of penicillin/streptomycin (GIBCO, USA) was added, and the thawed $T_{1}$ cells ( $174 \times$ CEM.T1, ATCC CRL-1991, USA) or 293T cells (GIBCO, USA) were put into $15-\mathrm{mL}$ centrifuge tubes, respectively. After centrifugation, the supernatant was discarded, and the cells were inoculated into culture flasks (Corning Company, China) and cultured in a $5 \% \mathrm{CO}_{2}$ incubator (Heal Force, Shanghai) at $37{ }^{\circ} \mathrm{C}$ with saturated humidity. The cells were passaged upon reaching $90 \%$ confluence $\left(25 \mathrm{~cm}^{2}\right)$.

\section{Cell transfection}

T1 cells that had grown well were treated with antibioticfree medium and single-cell suspensions $\left(1 \times 10^{5}\right.$ cells $\left./ \mathrm{mL}\right)$ were prepared. Then, the suspended cells were inoculated into $25-\mathrm{cm}^{2}$ cell culture flasks $(5 \mathrm{~mL} /$ vial). Three $2-\mathrm{mL}$ EP tubes were labeled as A, B and C. Tube A contained $250 \mu \mathrm{L}$ of serum-free antibiotic-free medium and $15 \mu \mathrm{L}$ of Lipofectamine 3000 reagent (Invitrogen, China), which were gently mixed; tube B contained $250 \mu \mathrm{L}$ of serumfree antibiotic-free medium and $15 \mu \mathrm{L}$ of Lipofectamine 3000 reagent (Invitrogen company, China), which were gently mixed; and tube $\mathrm{C}$ contained $500 \mu \mathrm{L}$ of serum-free antibiotic-free medium, $15 \mu \mathrm{g}$ of empty plasmid pEGFP-N2 (General Biosystems, China), and $20 \mu \mathrm{L}$ of P3000 reagent (Invitrogen, China), which were gently mixed. After culture in a $5 \% \mathrm{CO}_{2}$ incubator at $37^{\circ} \mathrm{C}$ with saturated humidity for 48 and $72 \mathrm{~h}$, the cells were harvested. Flow cytometry assay was performed to detect the proportion of EGFP-positive cells (green fluorescence) and to identify the optimal transfection conditions. The same procedure was carried out to transfect the 293 T cells. Although 293T cells are epithelial cells, they are often used as tool cells to improve transfection efficiency. Our experiments showed the transfection efficiency of $\mathrm{T} 1$ cell is very low. The purpose of this experiment is to verify the binding force between gp42 and HLA-DPB1 subtype, so we chose 293T cell as our experimental cells.

\section{Plasmid construction}

The chemically synthesized pEGFP-N2-HLA-DPB1 (General Biosystems) bacterial solution was plated on nutrient agar. First, the grown monoclonals were digested (EcoRI and BamHI), and then the positive clones were chosen for sequencing and alignment. To confirm whether the recombinant vector had been successfully constructed, polymerase chain reaction (PCR) was performed on the recombinant plasmids. These plasmids were divided into the blank control group, the empty vector group, and the HLA-DPB1 recombinant vector group.

\section{Detection of HLA-DPB1 expression level}

After the successful construction of the plasmids, flow cytometry (BD, USA) was performed to detect the proportion of EGFP-positive cells, the HLA-DPB1 gene expression level was determined by qRT-PCR (Applied Biosystems, USA), and Western blotting (Bio-Rad, USA) was used to measure the level of HLA-DPB1 protein expression.

\section{Detection of the HLA-DPB1 ${ }^{*}$ gp42 binding rate}

The $\mathrm{gp} 42 / \mathrm{gHgL}$ complex protein was labeled with $6 \mathrm{X}$ His antibody (QIAGEN, China), after which the protein fluoresced red. Under the optimal transfection conditions, the numbers of both green- and red-fluoresced T1 cells and $293 \mathrm{~T}$ cells under the electron microscope were counted to obtain the proportion of HLA-DPB $1^{+} \mathrm{gp} 42^{+}$cells; the HLA-DPB1 ${ }^{*}$ gp42 binding rate was calculated accordingly.

\section{Statistical analysis}

All data were expressed as mean \pm standard deviation $(\bar{x} \pm s)$. Statistical analysis was performed in SPSS 19.0 software package. Normally distributed data were analyzed with one-way ANOVA, with Fisher's least significant difference (LSD) method used for unequal variances and Tamhane test used for multiple comparisons with unequal variances. A P value of 0.05 was considered to be statistically significant. The non-normal set of data was normalized by logarithm transformation, followed by one-way ANOVA.

\section{Results}

\section{Properties of HLA-DPB1 *gp42 complex}

Molecular dynamics simulation using Discovery Studio 16.1 software showed that gp 42 protein bound to the $\beta$-chain 
A
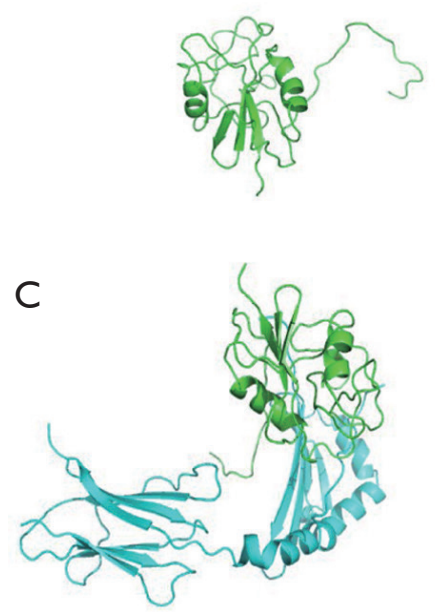

B

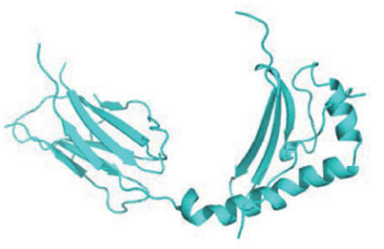

D

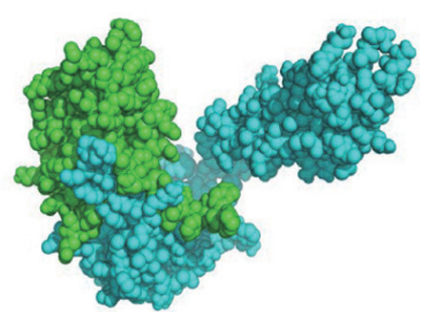

Figure 2 Docking simulation of HLA-DPB1*gp42 (by using ZDOCK). (A) $\alpha$-chain of gp42 protein; (B) $\beta$-chain of HLA-DPB1; (C) the complex formed by gp42 and HLA-DPB1; (D) 3D structure of the complex.

\begin{tabular}{|c|c|c|c|}
\hline Amino acids & 338 & No. of atoms & Resolution \\
\hline Molecular weight & $3,9144.12$ & PI & $3.25 \AA$ \\
\hline Gravy & -0.486 & Positive (Arg + Lys) & 33 \\
\hline Negative (Asp + Glu) & 34 & & \\
\hline Instability & 47.72 & Salt bridges & 0 \\
\hline Protein interface result & 7 & & E_Elec2 \\
\hline Pi interactions & 9 & & HLA-DPB1 \\
\hline Hydrogen bonds & -108.37 & 618.97 \\
\hline E_Vdw2 & gp42 & 278.00 \\
\hline $\begin{array}{c}\text { Contact surface area } \\
\text { Polar contact }\end{array}$ & 625.7 & & 340.97 \\
\hline $\begin{array}{c}\text { Surface area } \\
\text { Surface area }\end{array}$ & 312.03 & & \\
\hline
\end{tabular}

Figure 3 Properties of the HLA-DPB1* gp42 complex.

of HLA-DPB1 via its $\alpha$-chain (Figure $2 A, B$ ) to form a complex (Figure 2C). Figure 2D shows the 3D structure of the complex. As shown in Figure 3, the gp42*HLA-DPB1 complex was a hydrophilic protein containing a total of 338 amino acids and 5,370 atoms, with a molecular weight of $39,144.12$. An Instability index of 47.72 showed that the complex was unstable. Furthermore, 7 amino acids in the $\alpha$-chain were bonded with 7 amino acids in the $\beta$-chain via 9 hydrogen bonds. Table 1 shows the specific amino acid names and hydrogen bond distances.

\section{Optimal transfection conditions of 2937 cells}

After HLA-DPB1-containing plasmid vectors were constructed through transfection of T1 lymphocytes and $293 \mathrm{~T}$ cells, flow cytometry was performed to determine the optimal transfection conditions for T1 cells. The optimal concentration of Lipofectamine 3000 was $1.5 \mu \mathrm{L} /$ well and the optimal transfection time was $72 \mathrm{~h}$; however, the positive rate was only $8.467 \%$. The optimal transfection conditions for $293 \mathrm{~T}$ cells were also determined by flow 
Table 1 Hydrogen bonds

\begin{tabular}{lcccc}
\hline HLA-DPB1 residue & gp42 residue & Interaction constituents & \multicolumn{2}{c}{ Distance } \\
\hline B:LEU-17 & A:GLU207 & B:LEU-17:HN-A:GLU207:OE1 & 2.48 & Conventional \\
B:PHE-15 & A:HIS206 & B:PHE-15:HN-A:HIS206:O & 2.0305 & Conventional \\
B:ASN6 & A:TYR167 & B:ASN6:HD21-A:TYR167:OH & 1.9158 & Conventional \\
B:ARG12 & A:GLN89 & B:ARG12:HE-A:GLN89:OE1 & 2.7927 & Conventional \\
B:ARG12 & A:GLN89 & B:ARG12:HH21-A:GLN89:OE1 & 2.664 & Conventional \\
B:ARG32 & A:PRO91 & B:ARG32:HN-A:PRO91:O & 2.7459 & 2.5246 \\
B:ARG32 & A:VAL90 & B:ARG32:HH11-A:VAL90:O & 3.1432 \\
B:PRO-16 & A:HIS206 & B:PRO-16:CA-A:HIS206:O & 3.1472 \\
B:SER3 & A:THR95 & B:SER3:CB-A:THR95:OG1 & Carbon \\
\hline
\end{tabular}

cytometry. The optimal concentration of the transfection reagent was $1.5 \mu \mathrm{L} /$ well and the optimal transfection time was $48 \mathrm{~h}$; under such conditions, the proportion of EGFP-positive 293T cells was $55.233 \%$ (Figure 4), which was significantly higher than that of T1 cells. As the low transfection efficiency of the T1 cells was likely to result in a high false-negative rate, the $293 \mathrm{~T}$ cells, with their relatively high transfection efficiency, were subsequently used to detect the HLA-DPB1 ${ }^{*}$ gp42 binding rate. As shown in Figure 5, the quantitative results of Western blotting on 293 T cells after transfection showed significant differences between the blank control group, the empty vector group, and the HLA-DPB1 recombinant vector group.

\section{The optimal binding efficiency of HLA-DPB1 and gp42 protein}

The binding efficiency of HLA-DPB1 and gp 42 protein is shown in Figure 6. The binding efficiency of gp42 protein to HLA-DPB1 was highest at $80 \mu \mathrm{g}$ (Table 2). $293 \mathrm{~T}$ cells, which are epithelial cells derived from human embryonic kidney cells, contain plasmids containing SV40 large T antigen (Tag) origin of replication. As shown in Table 3, in the blank control group, the proportion of gp $42^{+}$cells was about $15 \%$. Meanwhile, the proportion of HLA$\mathrm{DPB}^{+} \mathrm{gp} 42^{+}$cells was significantly higher in the empty vector group than in the blank control group. These results suggest that 293T cells could also express proteins that can bind to gp42, among which the SV40 protein is highly probable. The proportions of gp $42^{+}$cells (\%), HLA-DPB $1^{+}$ cells (\%), HLA-DPB1 ${ }^{+}$gp $42^{+}$cells (\%) in the HLA-DPB1 recombinant plasmid group were significantly higher than

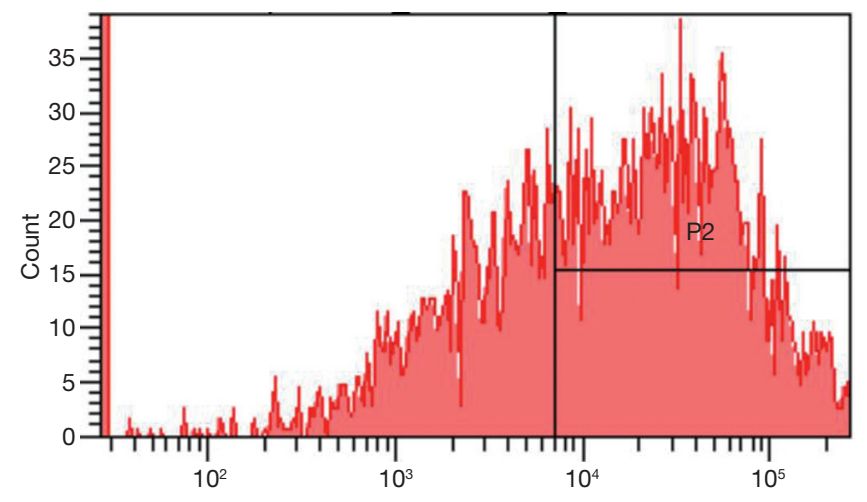

Figure 4 Flow cytometry was used to determine the optimal transfection conditions of $293 \mathrm{~T}$ cells $(1.5 \mu \mathrm{L} /$ well, $48 \mathrm{~h})$.

those in the blank control or empty control groups, which indicates that the plasmid protein could bind to gp42. In the blank control group, the proportion of HLA-DP ${ }^{+}$ gp $42^{+}$cells was consistent with that of HLA-DPB1 ${ }^{+}$cells. In the empty vector group and HLA-DPB1 recombinant plasmid group, the proportion of HLA-DPB $1^{+} \mathrm{gp} 42^{+}$cells was consistent with that of $\mathrm{gp} 42^{+}$cells. Therefore, the HLA-DPB1*gp42 binding efficiency in $293 \mathrm{~T}$ cells can be obtained by calculating the proportion of $\mathrm{gp} 42^{+}$cells. In our current experiment, the HLA-DPB ${ }^{*}$ gp 42 binding efficiency in $293 \mathrm{~T}$ cells was $26-31.3 \%$.

\section{Discussion}

EBV can infect both epithelial cells and B lymphocytes, although it is not clear which cell is infected first (15). Some studies have indicated that EBV first infects the 

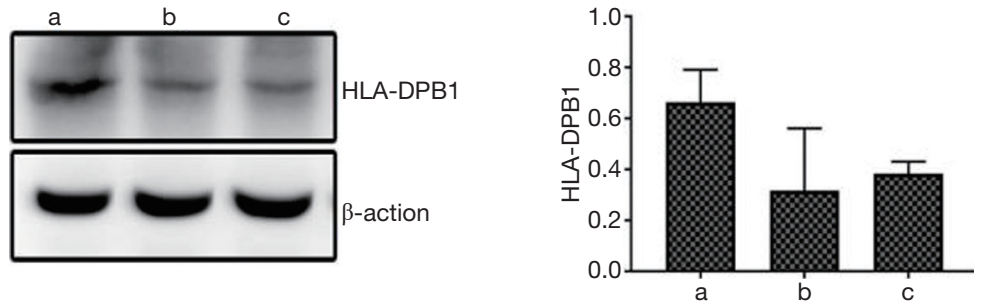

Figure 5 Western blotting (left: bands; right: qualitative Western blots. group a vs. b: $\mathrm{P}<0.05$; group a vs. c: $\mathrm{P}<0.05$ ). Note: a, HLA-DPB1 recombinant plasmid group; b, empty vector group; c, blank control group.

\begin{tabular}{|l|c|c|c|c|}
\hline Group & Blank control group & Empty vector group & $\begin{array}{c}\text { HLA-DPB1 } \\
\text { Recombinant plasmid } \\
\text { group }\end{array}$ \\
\hline $\begin{array}{l}\text { Dark } \\
\text { field }\end{array}$ & & & &
\end{tabular}

Figure 6 Fluorescence microscopy of 293T cells transfected with HLA-DPB1 recombinant vector.

Table 2 Concentrations of gp 42 protein in HLA-DPB $1^{+}$gp $42^{+}$cells by flow cytometry $(\bar{x} \pm s, \mathrm{n}=12)$

\begin{tabular}{|c|c|c|c|}
\hline gp42 protein $(\mu \mathrm{g})$ & HLA-DPB1+ $(\%)$ & $\mathrm{gp} 42^{+}(\%)$ & HLA-DP ${ }^{+}$gp $42^{+}(\%)$ \\
\hline 20 & $42.567 \pm 0.666$ & $13.967 \pm 0.153^{\nabla}$ & $12.400 \pm 0.100^{\nabla}$ \\
\hline 40 & $43.100 \pm 1.136$ & $20.100 \pm 0.781^{\mathbf{} \Delta}$ & $18.433 \pm 0.379^{\mathbf{v}}$ \\
\hline 80 & $42.900 \pm 1.015$ & $29.333 \pm 0.208^{\mathbf{V} \triangle \Delta}$ & $27.067 \pm 0.231^{\mathbf{v} \Delta \Delta}$ \\
\hline
\end{tabular}

${ }^{\nabla}, \mathrm{P}<0.05$, compared with $0 \mu \mathrm{g} ;{ }^{\triangle}, \mathrm{P}<0.05$, compared with $20 \mu \mathrm{g} ;{ }^{\wedge}, \mathrm{P}<0.05$, compared with $40 \mu \mathrm{g}$.

epithelial cells of the pharynx via saliva, and later infects B lymphocytes after it has self-replicated; however, it has also been argued that B lymphocytes may succumb to infection before epithelial cells (16). Both situations can co-exist. The manner in which EBV infects these two target cells differs.
EBV usually infects oral epithelial cells. The lymphocyterich tongue and tonsil tissues in the oral cavity present the EBV in oral epithelial cells with the opportunity to infect nearby B lymphocytes after replication (17). EBV infection of B lymphocytes does not directly lead to the development 


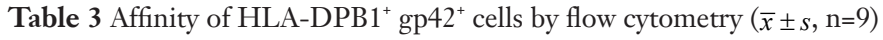

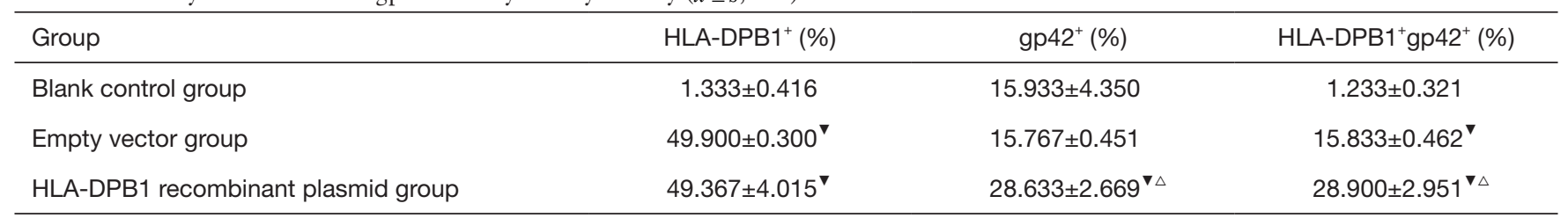

, $\mathrm{P}<0.05$, compared with the blank control group; ${ }^{\wedge}, \mathrm{P}<0.05$, compared with the empty vector group.

of HL; rather, the virus enters a stage of latent infection, during which the infected $B$ lymphocytes undergo lytic replication to renew the infected $\mathrm{B}$ lymphocytes in the surrounding gaps. Meanwhile, the release of EBV in saliva can infect epithelial cells in a more efficient manner (18). Thus, by shuttling back and forth between B lymphocytes and epithelial cells (19), the life cycle of EBV is repeated (16). As a result, individuals with normal immunity are asymptomatic, while immunocompromised patients may develop EBV-related diseases $(5,20)$. Möhl et al. found that EBV binds to its target cells in different ways: it infects B lymphocytes through endocytosis and infects epithelial cells through direct fusion with cellular membranes. Interestingly, no matter which cell is infected first or which infection pattern is applied, gp42 protein is always involved (10). Therefore, vaccines and treatments to fight EBV combine B-cell- and epithelial-cell-neutralizing antibodies to effectively block the entry of EBV via oral mucosa.

Compared with the pathogenesis of the influenza virus and HIV, the process of EBV infection of host cells is more complicated. During EBV infection, the membrane fusion and entry of the virus into cells are divided into multiple steps by the glycoproteins on its surface (21). Six EBV glycoproteins are typically found on the viral surface: gp 350 , gp220, gH, gL, gp42, and gB. Although the combinations of gp350 and gp220 with CR2 (CD21) can improve the efficiency of virus entry into host cells, they are not necessary for cell entry (22). The main function of $\mathrm{gB}$, the most conserved glycoprotein, is to promote the maturity of $\mathrm{EBV}$, and it is necessary for cell entry (23); however, it has been proposed that $\mathrm{gB}$ promotes virus-cell membrane fusion only under the regulation of $\mathrm{gH} / \mathrm{gL}$ (24). The gp 42 protein plays a central role in membrane fusion. As a directional switch (25), it can promote the fusion of EBV with B cells but inhibit the fusion of EBV with epithelial cells under the regulation of $\mathrm{gH} / \mathrm{gL}$ proteins $(23,26)$. However, the infected epithelial cells may be induced to express more HLA-II receptors and contain more gp42 (12). Importantly, the EBV-infected epithelial cells secrete some proteins (e.g.,
miR200s) that can stimulate the transformation of memory B lymphocytes from latent infection to proliferation, which is a basic step in the pathogenesis of HL (16).

The main function of HLA-II receptors is to present antigen (27). These receptors are predominantly expressed in conventional antigen-presenting cells including B cells, $\mathrm{T}$ cells, macrophages, and dendritic cells. Epithelial and endothelial cells can also be stimulated to express HLA-II receptors. The three different HLA-II molecules are HLADP, -DQ, and -DR (28). Each of these genotypes plays a critical role in EBV infection (29). In 2000, Haan et al. found the transient expression of HLA-DQ rendered EBV entry, and further research showed that only the HLA-DQ $\beta^{*} 02$ locus could regulate EBV entry (30). In 2002, Mullen et al. showed that the gp42 protein of EBV interacted with HLA-DR1 at a resolution of $2.65 \AA$ (13). Li et al. found that EBV infection of $\mathrm{B}$ cells could be impaired by blocking the interaction between gp42 and HLA-II molecules or blocking the conversion of gp42 into sgp42 (29). There is a hypothesis that the conformation of gp 42 changes slightly after HLA-II molecules bind to gp42, which rearranges the relevant glycoproteins in the viral envelope and alters the infection process, suggesting that gp 42 plays a key role during EBV infection (31).

Our current research confirmed that the $\beta$-chain of HLA-DPB 1 binds to the $\alpha$-chain of gp42 to form a complex, the secondary structure of which is stabilized by hydrogen bonds. Figure $2 \mathrm{D}$ and Table 1 present the $3 \mathrm{D}$ structure diagram of the binding pattern and the contact areas between these two chains, respectively. In addition, the transfection efficiency of HLA-DPB1 in T1 cells (B lymphocytes) and $293 \mathrm{~T}$ cells (epithelial cells) was measured using laboratory technology and the binding rate of $293 \mathrm{~T}$ plasmid vector to gp42 was calculated.

Unfortunately, due to the low proportion of EGFPexpressing T1 cells during the construction of the HLADPB1 vectors, the binding rate of T1 cells to gp42 was not further detected. Limited by our experimental conditions, we were unable to obtain B lymphocytes that 
neither expressed HLA-DPB1 nor carried EBV genes. Consequently, our subsequent experiment only revealed that the binding efficiency of HLA-DPB1 to gp42 in 293T cells was $26-31.3 \%$. In conclusion, the results of molecular dynamics simulation and laboratory tests in this study may help to improve our understanding of the pathogenic mechanism of HL caused by EBV infection of epithelial cells and B lymphocytes. Furthermore, tumorigenesis may be prevented by breaking hydrogen bonds, preventing hydrophilic binding, suppressing EBV activation, and lowering the concentration of gp 42 , and these strategies may also pave the way for effective therapies for treating HL.

\section{Acknowledgments}

Funding: Supported by the National Natural Science Foundation of China (NSFC): 81660035.

\section{Footnote}

Data Sharing Statement: Available at http://dx.doi. org/10.21037/tcr-20-2070

Conflicts of Interest: All authors have completed the ICMJE uniform disclosure form (available at http://dx.doi. org/10.21037/tcr-20-2070). The authors have no conflicts of interest to declare.

Ethical Statement: The authors are accountable for all aspects of the work in ensuring that questions related to the accuracy or integrity of any part of the work are appropriately investigated and resolved.

Open Access Statement: This is an Open Access article distributed in accordance with the Creative Commons Attribution-NonCommercial-NoDerivs 4.0 International License (CC BY-NC-ND 4.0), which permits the noncommercial replication and distribution of the article with the strict proviso that no changes or edits are made and the original work is properly cited (including links to both the formal publication through the relevant DOI and the license). See: https://creativecommons.org/licenses/by-nc-nd/4.0/.

\section{References}

1. Correia S, Bridges R, Wegner F, et al. Sequence Variation of Epstein-Barr Virus: Viral Types, Geography, Codon Usage, and Diseases. J Virol 2018;92:e01132-18.
2. Chen RW. Is there a place for the combination of brentuximab vedotin and bendamustine in treatment of patients with relapsed/refractory Hodgkin lymphoma? Ann Transl Med 2018;6:238.

3. M A, Chatterjee S, A P, et al. Natural Killer cell transcriptome during primary EBV infection and EBV associated Hodgkin Lymphoma in children-A preliminary observation. Immunobiology 2020;225:151907.

4. Liu ZL, Bi XW, Liu PP, et al. The Clinical Utility of Circulating Epstein-Barr Virus DNA Concentrations in NK/T-Cell Lymphoma: A Meta-Analysis. Dis Markers 2018;2018:1961058.

5. Saha A, Robertson ES. Mechanisms of B-Cell Oncogenesis Induced by Epstein-Barr Virus. J Virol 2019;93:e00238-19.

6. Chen YF, Chang CH, Huang ZN, et al. The JAK inhibitor antcin $\mathrm{H}$ exhibits direct anticancer activity while enhancing chemotherapy against LMP1-expressed lymphoma. Leuk Lymphoma 2019;60:1193-203.

7. Ahmed W, Tariq S, Khan G. Tracking EBV-encoded RNAs (EBERs) from the nucleus to the excreted exosomes of B-lymphocytes. Sci Rep 2018;8:15438.

8. Smatti MK, Al-Sadeq DW, Ali NH, et al. Epstein-Barr Virus Epidemiology, Serology, and Genetic Variability of LMP-1 Oncogene Among Healthy Population: An Update. Front Oncol 2018;8:211.

9. Bu W, Joyce MG, Nguyen H, et al. Immunization with Components of the Viral Fusion Apparatus Elicits Antibodies That Neutralize Epstein-Barr Virus in B Cells and Epithelial Cells. Immunity 2019;50:1305-1316.e6.

10. Möhl BS, Chen J, Longnecker R. Gammaherpesvirus entry and fusion: A tale how two human pathogenic viruses enter their host cells. Adv Virus Res 2019;104:313-43.

11. Snijder J, Ortego MS, Weidle C, et al. An Antibody Targeting the Fusion Machinery Neutralizes Dual-Tropic Infection and Defines a Site of Vulnerability on EpsteinBarr Virus. Immunity 2018;48:799-811.e9.

12. Trier N, Izarzugaza J, Chailyan A, et al. Human MHCII with Shared Epitope Motifs Are Optimal Epstein-Barr Virus Glycoprotein 42 Ligands-Relation to Rheumatoid Arthritis. Int J Mol Sci 2018;19:317.

13. Mullen MM, Haan KM, Longnecker R, et al. Structure of the Epstein-Barr virus gp42 protein bound to the MHC class II receptor HLA-DR1. Mol Cell 2002;9:375-85.

14. Morishima S, Shiina T, Suzuki S, et al. Evolutionary basis of HLA-DPB1 alleles affects acute GVHD in unrelated donor stem cell transplantation. Blood 2018;131:808-17.

15. Tsao SW, Tsang CM, Lo KW. Epstein-Barr virus infection and nasopharyngeal carcinoma. Philos Trans R Soc Lond 
B Biol Sci 2017;372:20160270.

16. Lin Z, Swan K, Zhang X, et al. Secreted Oral Epithelial Cell Membrane Vesicles Induce Epstein-Barr Virus Reactivation in Latently Infected B Cells. J Virol 2016;90:3469-79.

17. Chesnokova LS, Nishimura SL, Hutt-Fletcher LM. Fusion of epithelial cells by Epstein-Barr virus proteins is triggered by binding of viral glycoproteins $\mathrm{gHgL}$ to integrins $\alpha v \beta 6$ or $\alpha v \beta 8$. Proc Natl Acad Sci U S A 2009; 106:20464-9.

18. Möhl BS, Chen J, Park SJ, et al. Epstein-Barr Virus Fusion with Epithelial Cells Triggered by gB Is Restricted by a gL Glycosylation Site. J Virol 2017;91:e01255-17.

19. Borza CM, Hutt-Fletcher LM. Alternate replication in B cells and epithelial cells switches tropism of Epstein-Barr virus. Nat Med 2002;8:594-9.

20. Maurmann S, Fricke L, Wagner HJ, et al. Molecular parameters for precise diagnosis of asymptomatic EpsteinBarr virus reactivation in healthy carriers. J Clin Microbiol 2003;41:5419-28.

21. Sathiyamoorthy K, Hu YX, Möhl BS, et al. Structural basis for Epstein-Barr virus host cell tropism mediated by gp42 and gHgL entry glycoproteins. Nat Commun 2016;7:13557.

22. Kanekiyo M, Bu W, Joyce MG, et al. Rational Design of an Epstein-Barr Virus Vaccine Targeting the ReceptorBinding Site. Cell 2015;162:1090-100.

23. Plate AE, Reimer JJ, Jardetzky TS, et al. Mapping regions of Epstein-Barr virus (EBV) glycoprotein B ( $\mathrm{gB}$ ) important for fusion function with $\mathrm{gH} / \mathrm{gL}$. Virology 2011;413:26-38.
24. Chen J, Jardetzky TS, Longnecker R. The Cytoplasmic Tail Domain of Epstein-Barr Virus gH Regulates Membrane Fusion Activity through Altering $\mathrm{gH}$ Binding to gp42 and Epithelial Cell Attachment. mBio 2016;7:e01871-16.

25. Haan KM, Lee SK, Longnecker R. Different functional domains in the cytoplasmic tail of glycoprotein B are involved in Epstein-Barr virus-induced membrane fusion. Virology 2001;290:106-14.

26. Sathiyamoorthy K, Jiang J, Möhl BS, et al. Inhibition of EBV-mediated membrane fusion by anti-gHgL antibodies. Proc Natl Acad Sci U S A 2017;114:E8703-E8710.

27. Turrini R, Merlo A, Dolcetti R, et al. Differential downmodulation of HLA class I and II molecule expression on human tumor cell lines upon in vivo transfer. Cancer Immunol Immunother 2011;60:1639-45.

28. Haan KM, Kwok WW, Longnecker R, et al. EpsteinBarr virus entry utilizing HLA-DP or HLA-DQ as a coreceptor. J Virol 2000;74:2451-4.

29. Li Q, Bu W, Gabriel E, et al. HLA-DQ $\beta 1$ alleles associated with Epstein-Barr virus (EBV) infectivity and EBV gp42 binding to cells. JCI Insight 2017;2:e85687.

30. Haan KM, Longnecker R. Coreceptor restriction within the HLA-DQ locus for Epstein-Barr virus infection. Proc Natl Acad Sci U S A 2000;97:9252-7.

31. Kirschner AN, Omerovic J, Popov B, et al. Soluble Epstein-Barr virus glycoproteins gH, gL, and gp42 form a 1:1:1 stable complex that acts like soluble gp42 in B-cell fusion but not in epithelial cell fusion. J Virol 2006;80:9444-54.
Cite this article as: $\mathrm{Li} \mathrm{H}, \mathrm{Liu} \mathrm{D}, \mathrm{Li} \mathrm{X}$. HLA-DPB1 and Epstein-Barr virus gp42 protein jointly contribute to the development of Hodgkin lymphoma. Transl Cancer Res 2020;9(7):4424-4432. doi: 10.21037/tcr-20-2070 